\title{
Research on the Transformation and Upgrading of Rural Tourism Development in Chongqing Based on the Perspective of Supply-side Reform
}

\author{
Xuandong Li \\ Chongqing Business Vocational College
}

Keywords: Supply-side; Rural tourism; Reform

\begin{abstract}
The supply-side reform has become the new direction with the development of tourism industry, Chongqing city's tourism development as a key to fully implement the guiding ideology of the central supply-side reforms, focusing on the development of rural tourism in Chongqing based on the reform of the supply-side view. In this paper, the author combined with the actual situation in Chongqing, to explore the need of Chongqing rural tourism supply-side for reform and put forward the transformation and upgrading.
\end{abstract}

\section{Introduction}

In the economic work conference in the second half of 2015, the central government has stressed that the current domestic economy under the new normal must pay attention to the supply-side of structural reform, to strengthen the effectiveness of the supply system. At the same time, the domestic tourism industry experts suggested that the supply-side reforms as economic main subject of "13th Five-Year", which will give the domestic service industry especially the tourism industry to create an important opportunity for the domestic tourism industry transformation and upgrading. As a part of the tourism industry, rural tourism has been developing rapidly. In recent years, the development of Chongqing rural tourism, tourists continue to break the record, such as tourists in 2015 exceeded 120 million, revenue exceeded 21 billion yuan. At the same time, a series of effects of the tourism industry brought is also very prominent, the relevant data shows that since the rural tourism's development, which contributes to the development of Chongqing in many ways, the most direct expression is driving employment. Rural tourism has also led to the development of related industries in Chongqing City to solve a large number of employment problems. But at present, due to the traditional concept, economic level, infrastructure and other aspects of the impact of rural tourism in Chongqing City, there are still many problems such as the supply-side, the simple form, homogeneous, marketing strategy is not clear, the management and service level is still low. In view of these problems, based on the perspective of supply-side reform, Chongqing City is necessary to carry on the reform of rural tourism supply-side structure, changing the traditional concept to optimize the effectiveness of the supply system. For example: to increase rural tourism investment level, timely construction of infrastructure, and continuously improve the level of project, improve tourist routes, optimize product innovation, establish the rural tourism brand, improve rural tourism management and service level, and vigorously promote the supply-side reform of Chongqing rural tourism.

\section{The Necessity of Reform of Supply-side in Rural Tourism of Chongqing}

At present, the rural tourism industry in Chongqing is mainly faced with the problem of irrational supply structure, the imbalance between supply and demand and the poor efficiency of supply, so it is necessary to reform and upgrade the supply-side. The demand of tourism is growing rapidly, but the supply structure is not reasonable, the traditional low-end products is too high and the quality of the product is in short supply. Bound shopping, tourism products in the same size, uneven suppliers, complaints and so on mean the problem that the current supply of rural tourism in Chongqing is still not good to meet the needs of tourists. This also shows that the biggest obstacle to the healthy development of Chongqing rural tourism in the future is the imbalance of supply structure. And 
blind pursuit of rapid growth in the scale results in a variety of problems' arise. To remediation chaos of rural tourism in Chongqing, to adjust, optimize the rural tourism supply-side structure the is the most important task and work during the period of 13th Five-Year, and the diversification should be based on market demand, improving the effectiveness of the supply system, the contradiction between the supply and demand side. In view of the diversity and complexity of the current market's demand, taking targeted service system to ensure that the policy can be implemented to improve its effectiveness should be paid attention currently by tourism industry of Chongqing.

The reform of rural tourism supply-side structure will vigorously promote the transformation and upgrading of rural tourism in Chongqing. At present, Chongqing rural tourism has a lot of problems such as products are too simple, the tourist area is too similar, a serious shortage of high quality products, service level is not high and the problem of tourism and leisure imbalance and so on, the contradiction between the supply and demand side has become increasingly prominent. Based on this situation, in order to alleviate and improve its current state, it can start from the two aspects of policy and market firstly, mobilizing the enthusiasm of the people with most people's power. Secondly, in terms of policy, by reforming the supply-side measures to optimize the industrial structure. Only by making full use of the factors of both sides can it continuously optimize the industry and promote the upgrading of the industry.

\section{Basic Points of the Transformation and Upgrading in Chongqing Rural Tourism Supply- Side}

Transformation and Upgrading of Product. The reform of rural tourism products in Chongqing is to optimize the structure of tourism products based on the demand of the market in real time, and to develop a product structure with diversified and full range. The products of rural tourism in Chongqing are still in a primary position with many tourist types that based on farmers' supply, which formed the scale having the problems of uneven dispersion, lack of leisure and too similar characteristics, such as lack of experience. However, the current market demand has changed, the tourists began to favor diversified, high-quality tourism products, and gradually tend to have a higher leisure and experience of the type.

Chongqing rural tourism products can reform existing rural tourist attractions based on the characteristics of tourism products by mining, the development of multi-level development. And then focus on rural tourism products such as leisure, vacation, Leisure Village Manor farmhouse and farm sanatorium. The development of leisure, vacation, recreation and entertainment can meet the diverse needs of the tourists. Experience can encourage development of rural tourism products, such as agricultural labor, rural festive experience and experience of rural culture learning through product portfolio with the rural cultural activities promoting rural tourism to participate in the experience of model transformation.

The reform of rural tourism products should not only attach importance to the development and utilization of basic resources, but also make good use of rich rural resources, at the same time to deeper development, pay more attention to the cultural connotation of tourism products with the rural cultural elements, so as to promote the quality of product improving the leisure and experience in rural tourism product proportion which optimize the product structure keeping up with the rigid demand of tourists.

Transformation and Upgrading of Industrial Structure. The tourism industry can be divided into five parts including diet, accommodation, transportation, shopping and entertainment. The former three are the basic consumption category, and the latter two belong to the flexible consumption. Consumption structure imbalance is a long-term problem in domestic tourism consumption industry with the proportion of basic consumption remains high and the elasticity of consumption cannot be taken up. This country has introduced a series of policies to promote tourism shopping consumption, and tourism bureau also held a variety of special exposition for the region's tourism industry to guide the direction of reform. However, over the past few years, the status of domestic tourism consumption structure has not been much improved, the proportion of 
tourism shopping and entertainment revenue in the total income almost has no growth.

Chongqing rural tourism also has a similar problem, such as the proportion of basic tourism consumption with food and housing consumption are too high which lead to the proportion of entertainment and shopping consumption is small and the structure is not balanced. To solve this problem, it is necessary to reform the rural tourism industry structure of tourism products such as rural products, porcelain and souvenirs to increase investment and the diversity of rural tourism products, increasing the proportion of shopping. At the same time, it can carry out leisure reform for the entertainment consumption based on the demand of tourists' leisure vacation for characteristics of rural tourism to promote the consumption of rural tourism and entertainment.

Transformation and Upgrading of Production Factors. The nature of the reform of rural tourism supply-side is to reform the related factors and stimulate the productivity of the related factors. More specifically, it is to promote the flow of people, land, capital and technology and other factors, optimize or adjust the allocation of these factors of production resources to ensure the quality of Chongqing rural tourism industry's growth. In this regard, Chongqing rural tourism need to get the way to change from the macro management system, so that the relevant factors of production glow through the market to optimize the combination.

(1) The aspect of people. This is a key step, only by increasing the human capital investment, pay attention to relevant professional managers or general practitioners in terms of comprehensive training improving their service quality and delivery of high quality talents for rural tourism labor market. In order to attract more tourists and to increase the good impression of tourists, rural tourism industry practitioners should organize some special projects or training, in order to improve their working ability and quality, so as to promote the development of rural tourism.

(2) The aspect of the land. For rural tourism land allocation and utilization of scarce land indicators, they do not only need payment audit, but also in a timely manner of rural tourism land supply to realize land transfer can be flexible with good land and good rural tourism projects.

(3) The aspect of capital. The development of rural tourism not only need to increase capital investment, but also need to optimize the structure of capital, and actively explore the diversification of financing channels. Specifically, one needs to make good use of agriculture, forestry, support, culture and other departments to actively acquire resources and national fiscal policy funds for rural tourism support. And it is the use of non-government capital, through some good rural tourism projects, to attract private capital flows. It can be realized through financial intermediaries such as financing, such as the mortgage loans to some national policy banks.

(4) The aspect of the consumer environment. At present, Chongqing rural tourism consumption environment still have many problems, such as the consumption of soft environment, lack of consumer confusion in the market competition and the integrity of the mechanism causing tourists lack of consumer confidence. And the consumption of rural tourism related hardware environment, the infrastructure is backward, so the conditions of Tourism health also needs to be improved which is not conducive to the growth of consumption of tourists.

On the reform of Chongqing rural tourism consumption environment, it must carry out rectification of tourism consumption of soft environment in various regions, in order to formulate industry regulations, strengthen the cooperation between departments, severely punished in violation of operating regulations of the tourism business, maintain rural tourism market order. And it also need to build the hardware environment of rural tourism with the use of environmental technology to strengthen construction, road construction, good green environment, medical conditions and health conditions to provide quality consumption environment for tourists which attract more capital investment.

\section{Conclusion}

This article is based on the reform of the supply-side, and with this it is combined with the analysis of the current status of tourism in Chongqing, focusing on the description of the several major basic points of reform for supply-side in Chongqing rural tourism, to realize diversification of tourism products, the development of characteristics, and constantly optimize the industrial structure and 
consumption environment and so on which can better keep up with the demand of tourists' leisure or vacation with solving the problem of the supply and demand and improving the effectiveness of rural tourism's supply system in Chongqing.

\section{References}

[1] ZuoXiaoJuan, yu yong. Accurate guide for poverty alleviation of rural tourism supply side innovation research [J]. Journal of China informatization management. 2016 (10)

[2] Jin-hai xu and long Xia Jie. Thinking on the reform of supply side to promote China's tourism products system [J]. Journal of hebei province. 2016 (3)

[3] Sun Li, Zhi-bo ma, zhang yi. Basis of maritime English tutorial [M]. Dalian: dalian maritime university press, 2012:149-151.

[4] Yang Fengning. Comparison and translation between English and Chinese language [M]. Tianjin: tianjin university press, 2012:136-138.

[5] Zhao Xuan, Zheng Yang. English translation of science and technology [M]. Beijing: foreign language teaching and research press, 2013:405-406

[6] Huang jing. Maritime English translation problems [J]. Journal of Shanghai maritime university, 2012, 29 (12): 391-392. 